\title{
Airport capacity evaluation based on air traffic activities big data
}

\author{
Lili Wan ${ }^{1,2}$, Qiuping Peng ${ }^{2}$, Yong Tian² ${ }^{2}$, Lei Gao ${ }^{2}$ and Bojia Ye ${ }^{2}$
}

\author{
${ }^{*}$ Correspondence: \\ tianyong@nuaa.edu.cn \\ ${ }^{2}$ College of Civil \\ Aviation, Nanjing \\ University of Aeronautics \\ and Astronautics, \\ Nanjing 210016, People's \\ Republic of China \\ Full list of author information \\ is available at the end of the \\ article
}

\begin{abstract}
In order to evaluate the airport's comprehensive service capabilities, this paper considers the impact of air quality and noise on the airport environment under the big data of air traffic activities. In this study, the concept of environmental traffic capacity and big data are applied to the air traffic field. Recently, the airport air and noise pollution has been widely investigated and has become one of the major concerns of the potentially exposed people. This study explores the usage of governmental ambient air quality and noise standards to evaluate the airport operation capacities in the context of the era of big data. The first step is to analyze the typical airport operation scenario as the evaluation scenario. The second step is to use the air and noise emission assessment model for calculating the airport maximum air pollutant concentration and noise level. The final step is to establish a complete airport environment traffic capacity (AETC) evaluation process. As a case study, the capacity evaluation of Nanjing Lukou international airport (NKG) is performed using the above steps. In this case, significant associations between the pollutant concentrations/noise level and the air traffic volume were observed. The AETC of NKG was calculated with the established evaluation process successfully. The results show that the NKG maximum hourly air traffic volume is 120, daily air traffic volume is 770, and annual air traffic volume is 365,805, meeting the China Ambient Air Quality and Noise Standards. Although different air pollutants were investigated in this research, only the $\mathrm{NO}_{x}$ was found to be the species that approaching the China governmental standards in this case. Thus, the airport $\mathrm{NO}_{x}$ concentration was selected as the AETC limitation factor.
\end{abstract}

Keywords: Airport, Air emission, Environment capacity, Noise

\section{Introduction}

Airport is the regular place for flights to take off, land and carry out ground activities. Civil airports are not only a key link in air traffic, but also a hot spot for people's livelihood. With the global economic and social development, the air traffic volume has increased rapidly in the past decades. At the airport, flight delays and conflicts occur frequently, and the airport has become a critical bottleneck for air traffic due to the imbalances in supply and demand. In order to use airport resources more safely and efficiently, a specific and accurate airport service capacity evaluation method is necessary and important [1]. Currently, the capacity evaluation methods are limited to the factors such as the airport physical structure, navigation facilities, operating rules and author(s) and the source, provide a link to the Creative Commons licence, and indicate if changes were made. The images or other third party material in this article are included in the article's Creative Commons licence, unless indicated otherwise in a credit line to the material. If material is not included in the article's Creative Commons licence and your intended use is not permitted by statutory regulation or exceeds the permitted use, you will need to obtain permission directly from the copyright holder. To view a copy of this licence, visit http:// creativecommons.org/licenses/by/4.0/. 
air traffic controllers' workload. With the increase in environmental awareness and the sustainability needs, there is a growing concern regarding the environmental impact of air traffic. In the context of the era of big data, air traffic activities will also generate a large number of diverse and realistic data sets. Air and noise emissions are the two main branches of these data sets. It can provide data support for airport capacity evaluation. It has therefore become popular to take the air traffic environmental capacity into consideration based on big data under airport air traffic activities when to achieve a "win-win" situation in terms of transportation development and environmental conservation.

The concept of environmental traffic capacity (ETC) was first time brought up by Buchanan in 1963 [2]. According to the study, ETC refers to the largest development scale that a traffic environment can withstand without any damage to human survival, ecological environment and use of resources in a certain time period and a region with certain traffic structures. The concept of ETC has been widely used in urban traffic, road traffic and waterway transportation. Huang proposed a double-decision optimization model to obtain the maximum urban traffic under the constraint of noise environmental capacity [3], Du adopted the multi-objective programming model to describe the relationship between traffic emission and urban traffic based on the traffic environmental capacity and macroscopic fundamental diagram theory [4], Wang established the road section environmental traffic capacity optimization model and used the improved augmented Lagrange function to solve the model [5] and determined the waterway traffic capacity by the minimum stopping distance prediction model [6], and the existing research generally studies the relationship between environment and traffic by different model to calculate the maximum traffic volume as ETC. In air traffic, some scholars have also paid attention to the environmental impact, but there is no in-depth research on ETC so far $[7,8]$.

The concept of airport capacity was defined in the middle of last century, and it refers to the expected number of movements that can be performed in unit time on an airport system without violating air traffic management (ATM) rules, assuming continuous aircraft demand [1]. For example, scholars have proposed numerical formulas for calculating airport capacity based on the number and layout of runways [9]. SOME simulation tools, such as SIMMOD, TAAM, RAMS and AirTOp, can simulate the whole airport operation process to obtain the maximum capacity corresponding to acceptable flight delay level [10]. Sometimes, the maximum hourly air traffic volume based on the terminal sector controller workload is also applied as the airport capacity [11]. In summary, current models and evaluation methods of airport capacity are based on physical structure, acceptable flight delays and the workload of terminal controllers, but not considering any environmental factors.

However, the impact of aircraft activities on the environment cannot be ignored with the increase in concerns of human health. Although there is no research performed on airport ETC, many scholars have carried out studies on the impact on the surrounding environment brought by aircraft activities. For example, many previous airport environmental studies focused on the noise and generated by the airport operations [12].

The air emissions from aircraft activities can also affect ambient air quality [13, 14] and harm human health [15-17]. Xia et al. calculated the landing and take-off (LTO) cycle pollutant emissions using the International Civil Aviation Organization (ICAO) 
Emission Databank (EDB) and summarized the relationship between the number of LTOs and pollutant emission index [18]. Massachusetts Institute of Technology (MIT) Laboratory for aviation and the environment proposed rapid operational air quality modeling $[19,20]$ and develop a response surface model (RSM) [21] to assess the impact of aviation emissions on air quality in the USA. ICAO Doc 9889 has given the reference calculation method for various polluting gases [22]. Kurniawan et al. analyzed the advantages and disadvantages of all airport pollutant emission assessment methods and determined the uncertainty of each method [23]. Wasiuk et al. built an aircraft performance model implementation (APMI) system based on aircraft performance models and regression methods to predict aircraft fuel consumptions and pollutant emissions [24]. Federal Aviation Administration (FAA) has released the Aviation Environmental Design Tool (AEDT 2c), which can be used to calculate pollutant emissions of aircraft and flight flow [25]. Dragana used historical data to analyze the relationship between meteorological conditions and pollutant emissions [26].

Many adverse effects have been related to noise exposures, such as hearing loss, hypertension [27], myocardial infarction [28], learning impairment [29] and annoyance [30]. The airport noise pollution affects surrounding residents [31] and the land use [32]. In 2014, Gaetano et al. used the integrated noise model (INM) to evaluate civil and military airport noise of different scenarios and improved the model input accuracy by automatic identification system (AIS) [33]. In 2017, Gasco et al. reviewed the importance of communicating airport noise information to the public noise indicators and examined the methods of representing noise data by using visualization strategies and new tools [34]. In 2018, Gagliardi et al. derived the noise model by using principal component analysis and multiple linear regression, and the model produced a good sound exposure level estimation [35, 36].

The concept of big data was first proposed by Viktor Mayer-Schönberger and Kenneth Cukier in 2013. It has volume, velocity, variety, veracity and other characteristics. It is the product of rapid technological development. With the advent of the cloud era, big data have attracted more and more scholars' attention and is widely used in the field of artificial intelligence. Traffic activities data are huge and complex, with digital and image in formats, which need to be processed by big data methods before it can be applied to the corresponding research. Traffic activities big data can use deep learning [37], intelligent video analysis [38], dictionary learning model [39] and other methods [40]. However, as far as the environment is concerned, the impact of data such as air and noise emissions from air traffic activities on airport capacity cannot be ignored. The modeling method based on big data of air and noise emissions is also applicable to the evaluation of airport capacity.

In order to ensure that the airport surroundings are not compromised, an airport ETC should be set up to make the airport development sustainable. To avoid confusion, this study used the name of "airport environment traffic capacity (AETC)" as the airport ETC, to compare with city or water traffic ETC. The objectives of this study are to:

1 Calculate the pollutant concentration and noise level of receptor points around airport in certain airport operation condition; 
2 Analyze the relationships between air traffic volume and pollutant concentration/ noise level;

3 Find the proper air quality standard and noise standard to set up the AETC. Since the AETC considering air and noise emissions are first time proposed and the evaluation method is novel, the Nanjing Lukou international airport (NKG) was selected as a case study to validate the calculation method.

The remainder of the paper is organized as follows. In "Method" section, the evaluation method of AETC is introduced and pollutant concentration assessment model is established; In Section III, the reliability and applicability of the method is verified by using actual operation data of NKG. Finally, this paper is concluded in "Results and discussion" section.

\section{Method}

\subsection{AETC}

When the airport has a small amount of air traffic, the air pollutant concentration is within the range of the environment's self-purification capability, and the noise is within tolerable range of human beings. With the airport air traffic flow increases, the air pollutant concentrations and noise level increase as well. To protect the environment, AETC is defined as the maximum airport air traffic volume (the number of aircraft movements) in unit time without causing environmental degradation. In other words, the AETC is the maximum airport operations that an airport can accommodate in unit time to meet ambient air quality and noise standards with a given airport's structure and operating rules, which can be expressed as:

$$
\mathrm{AETC}=\min \left(\mathrm{AETC} \_\mathrm{A}, \mathrm{AETC} \_\mathrm{N}\right)
$$

where AETC_A is the maximum air traffic volume (ATV) that an airport can accommodate in unit time to meet ambient air quality standards with a given airport's structure and operating rules, the air quality standards prescribe the limitation for the pollutant concentration (PC) of various air emission gas. AETC_N is the maximum air traffic volume that an airport can accommodate in unit time to meet noise standards with a given airport's structure and operating rules, the noise standards prescribe the limitation for the noise level (NL) of noise exposure. Figure 1 is a schematic diagram showing the relationship between air traffic volume and $\mathrm{PC} / \mathrm{NL} . \mathrm{PC}=\mathrm{f} 1$ (ATV) is the pollutant concentration of air emission restricted point; $\mathrm{NL}=\mathrm{f} 2(\mathrm{ATV})$ is the noise level of noise emission restricted point.

\subsection{Pollutant concentration (PC) assessment model}

- Airport air emission inventory

This study mainly considers the air pollution sources related to airport operation, which can be roughly divided into three categories: aircraft, ground support equipment (GSE) and ground transportation surrounding airport.

ICAO points out that the controlled air pollutants are $\mathrm{NO}_{x}, \mathrm{HC}$ and $\mathrm{CO}$ [41]. In addition, China's air quality assessment also focuses on inhalable particulate matter PM10. 


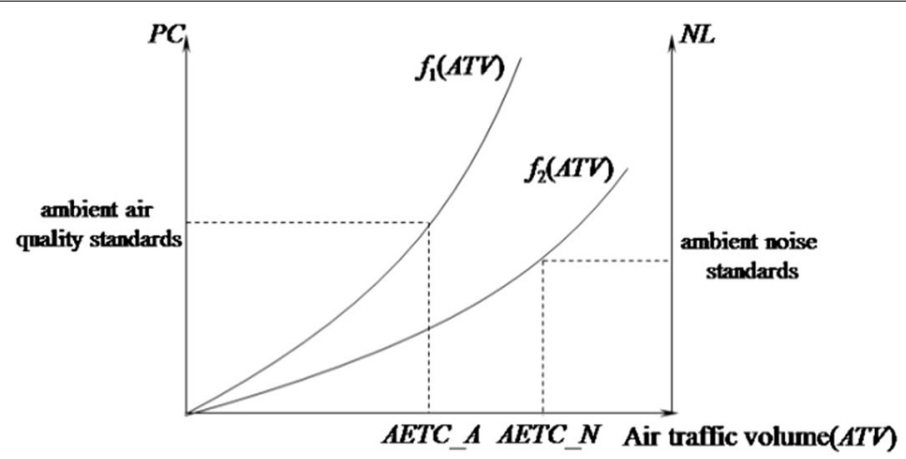

Fig. 1 Relationship between air traffic volume and PC/NL

The air emissions of ground support equipment and motor vehicles are also these four gases. Therefore, engine emission and APU emission, the inventory of the aircraft emission can be calculated by:

$$
E_{m}^{A}=n \cdot \mathrm{FF} \cdot \mathrm{EI}_{m} \cdot t
$$

where $n$ is the engine number of aircraft; FF is the fuel flow $(\mathrm{kg} / \mathrm{s})$, which can be calculated by the method of Base of aircraft data (BADA) [42] and first-order approximation (FOA) [43]; $\mathrm{EI}_{m}$ is the emission index of gas $m(\mathrm{~g} / \mathrm{kg})$, the reference value can be obtained from ICAO databank [44]; $\mathrm{t}$ is flight time (s).

The GSE emissions are associated with the aircraft which operates in airport [45] can be calculated by:

$$
E_{m}^{S}=\sum_{j} \mathrm{EF}_{j, m} \cdot t_{j, i}
$$

where $\mathrm{EF}_{j, m}$ is the gas $m$ emission factor of GSE class $j(\mathrm{~g} / \mathrm{s}) ; t_{k, j}$ is the operational time of GSE class $j$ service for aircraft $i$ (s).

The emissions of ground transportation can be calculated by:

$$
E_{m}^{G}=\mathrm{EC}_{m} \cdot L
$$

where $\mathrm{EC}_{m}$ is the gas m emission coefficient of motor vehicle $(\mathrm{g} / \mathrm{km})$, the reference value can be obtain in the technical guide [46]; $L$ is the travel distance of motor vehicle $(\mathrm{km})$.

- Gaussian diffusion model

This paper uses the American Meteorological Society/Environmental Protection Agency Regulatory Model (AERMOD) to assess the air pollutant concentration around the airport; the diffusion model is Gaussian diffusion model.

The air pollutant concentration is the sum of each air pollution source which is calculated, respectively. The pollutant concentration $\mathrm{PC}(x, y)$ of any receptor point $(x, y)$ near the airport can be expressed as:

$$
\mathrm{PC}(x, y)=\sum_{k} \mathrm{PC}_{k}(x, y)
$$


where $\mathrm{PC}_{k}(x, y)$ is the pollutant concentration of pollution source $k$ at receptor point $(x$, $y)$.

Some part of aircraft movements emits air emissions and spread into the atmosphere along the trajectory, such as take-off, landing, climb, and descent. The emission patterns can be considered as line source, so do ground transportation.

The pollutant concentration $\mathrm{PC}_{k}(x, y)$ generated by the line source $\mathrm{k}$ formed by aircraft can be expressed as:

$$
\begin{aligned}
\operatorname{PC}_{k}(x, y)= & \frac{\mathrm{SS}_{k}}{\sqrt{2 \pi} V_{\mathrm{W}} \sigma_{y, k} \sigma_{z, k}} \times\left\{\exp \left[-\frac{\left(z-H_{k}\right)^{2}}{2 \cdot \sigma_{z, k}^{2}}\right]+\exp \left[-\frac{\left(z+H_{k}\right)^{2}}{2 \cdot \sigma_{z, k}^{2}}\right]\right\} \cdot \frac{1}{\sqrt{2 \pi}} \\
& \times \int_{-l_{k}}^{l_{k}} \exp \left(-\frac{\left(y_{k}\right)^{2}}{2 \cdot \sigma_{y, k}^{2}}\right) \mathrm{d} y
\end{aligned}
$$

where $V_{\mathrm{W}}$ is the wind direction; $y_{k}$ is the distance between the line source $k$ and the origin; $\sigma_{y, k}$ and $\sigma_{z, k}$ are the diffusion coefficient [47]; $\mathrm{SS}_{k}$ is the emission intensity of the line source $k: \mathrm{g} /(\mathrm{m} \mathrm{s}), k \in\{$ take-off, landing, climb, descent, ground transportation\}; $z$ is the height of receptor point; $H_{k}$ is the average height of the line source $k ; l_{k}$ is half the length of line source $k$.

The aircraft taxiing trajectory can be regarded as a planar network, and the diffusion model of the gas pollutant emission is the typical area diffusion model [48]. The Gaussian area source diffusion can be transformed into a virtual point source Gaussian diffusion model.

$$
\mathrm{PC}_{k}(x, y)=\frac{\mathrm{SS}_{k}}{\pi V_{W}\left(\sigma_{y, k}+a_{k} / 4.3\right) \sigma_{z, k}} \cdot \exp \left[-\frac{y^{2}}{2 \cdot\left(\sigma_{y, k}+a_{k} / 4.3\right)}\right]
$$

where $a_{k}$ is the length of the area source $k$; $\mathrm{SS}_{k}$ is the emission intensity of the virtual pollution point source $k$.

\subsection{Noise level (NL) assessment model}

This study mainly considers the noise emission caused by aircraft. The noise will affect residents near the airport when flying below 10,000 feet. China adapts the weight equivalent continuous perceived noise level (WECPNL) [49] to describe the noise level, which can be expressed as:

$$
\begin{aligned}
& \mathrm{NL}(x, y)=\operatorname{WECPNL}(x, y)=\overline{L_{\mathrm{EPN}}(x, y)}+10 \cdot \log \_10\left(N_{1}+3 \cdot N_{2}+10 N_{3}\right)-39.4 \\
& \overline{L_{\mathrm{EPN}}(x, y)}=10 \cdot \log _{-} 10\left[\frac{1}{N \cdot T_{0}} \cdot \sum_{i} \sum_{j} \sum_{m} 10^{0.1 \cdot L_{\mathrm{EPN}_{i j m}}(x, y)}\right]
\end{aligned}
$$

where $\mathrm{N} 1$ is the air traffic volume in the daytime 07:00-19:00; $\mathrm{N} 2$ is the air traffic volume in the evening time 19:00-23:00; N3 is the air traffic volume in the nighttime 23:0007:00. $\overline{L_{\mathrm{EPN}}}$ denotes the average value of the effective perceived noise level (EPNL), 
where $\mathrm{T} 0$ is the reference time, equals to $10 \mathrm{~s}, L_{\mathrm{EPN}_{i j m}}(x, y)$ represents single event noise level at point $(x, y)$ when aircraft $i$ is flying along the leg $m$ of route $j$, which can be calculated by regression analysis and using the NPD data of INM or ANP (ICAO Doc9911) [50].

\subsection{Evaluation process}

AETC is the maximum air traffic volume which is allowed by ambient air quality and noise standards. At present, the air and/or noise emissions around the airport do not exceed the standards usually which means that the air traffic volume is not saturated. Refer to the evaluation method of airport capacity, the AETC evaluation is carried out by increasing the air traffic volume in accordance with certain laws to obtain the maximum air traffic volume which can satisfy the ambient air quality and noise standards. The method flow of evaluation is as follows:

\section{- Analyze the airport operational characteristics}

According to the pollutant concentration and noise level assessment model, the relevant airport operational characteristics include the distribution characteristics of air traffic flow and aircraft type, airspace structure, airport layout, runway operational mode, meteorological conditions, etc. It is necessary to analyze the historical data by the statistics method; then, the evaluation method chooses the worse operational scenario which has the most serious impact on the environment and uses it as the airport operational typical scenario to evaluate AETC.

- Find the air and noise emissions receptor points

In order to compare the evaluation results of different receptor points effectively, the coordinate system is set up according to the airport layout, the origin is the runway center (the upwind direction runway is selected in a multi-runway airport, if the airport has intersecting runways, the runway which has the bigger angle between runway direction and wind direction will be selected), the $Y$ axis is along the runway direction, the $X$ axis is perpendicular to the $Y$ axis and points to the main area of airport, and the $Z$ axis is the height. According to the requirement of air quality and noise standards, we search topographic map to find sensitive points such as villages, hospitals, schools, etc., and label them in the coordinate system as receptor points.

- Calculate pollutant concentration and noise level

By using the "Pollutant concentration (PC) assessment model" section and the "Noise level (NL) assessment model" section, the $\mathrm{PC}(x, y)$ and $\mathrm{NL}(x, y)$ of any receptor points ( $x$, $y$ ) in the coordinate system can be calculated in the airport operational typical scenario. So the pollutant concentration and noise level of each receptor points are prepared, we can select the point with the greatest environmental impact as the restricted point; PC and $\mathrm{NL}$ are $\mathrm{PC}(x, y)$ and $\mathrm{NL}(x, y)$ of the restricted point, respectively.

- Construct the correlation between air traffic volume and the PC/NL

If $\mathrm{PC}$ and/or NL are less than the standards, the air traffic flow must be cloned to increase the air traffic volume. According to airport operational characteristics, the 
increment air traffic flow has the same characteristics with the existing air traffic flow. The PC and NL can be calculated by the way mentioned above and using the incremental air traffic flow, and quantify the correlation between airport air traffic volume and the $\mathrm{PC} / \mathrm{NL}$.

- Determine the AETC

The AETC_A is determined by the correlation between air traffic volume and the PC; the AETC_N is determined by the correlation between air traffic volume and the NL. According to the ambient air quality and noise standards, we can obtain the AETC_A and AETC_N, respectively, and use Eq. (1) to determine AETC.

A specific method flow of evaluation method is shown in Fig. 2.

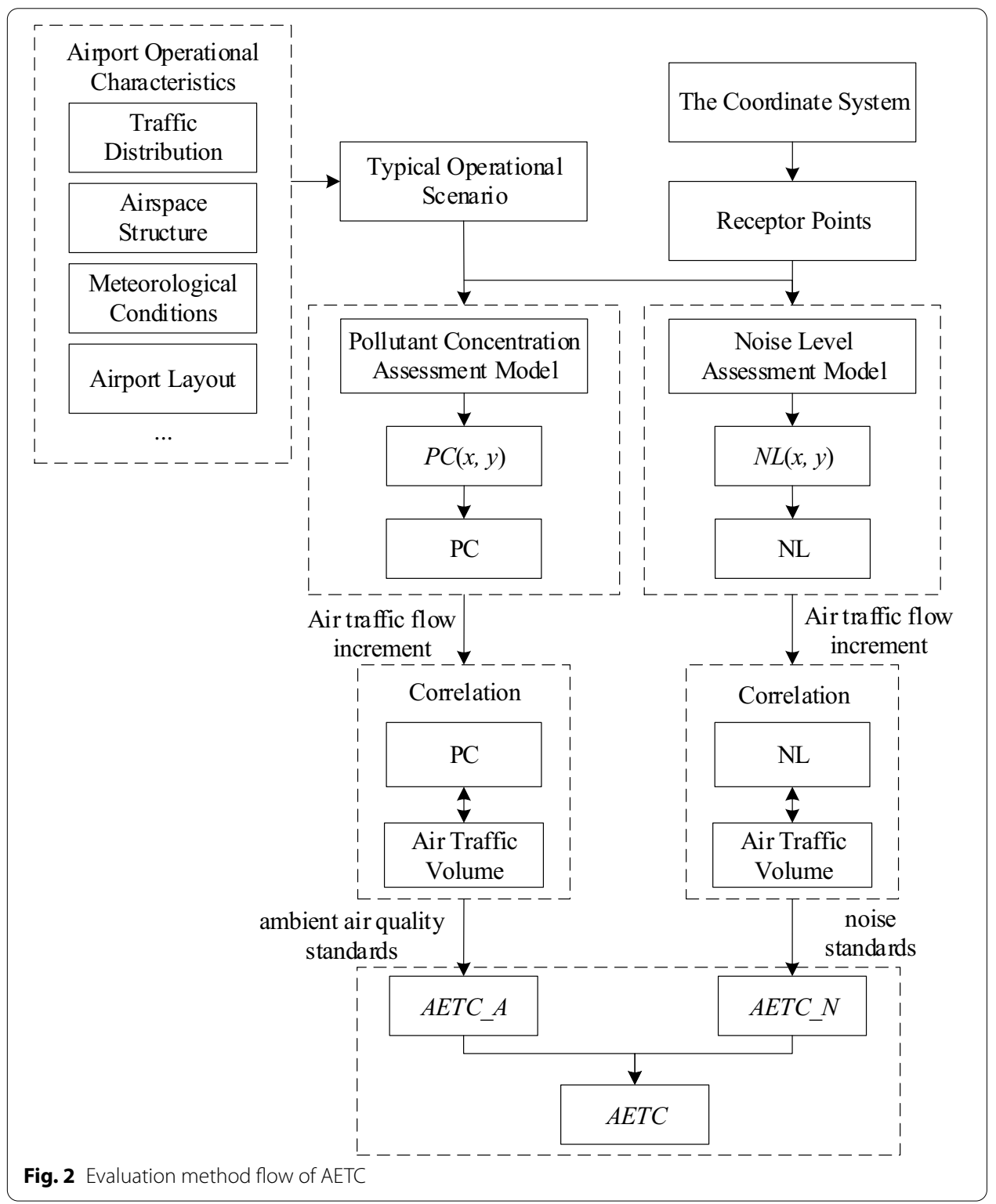




\section{Numerical test}

In this study, NKG is selected to evaluate AETC according to the above evaluation process.

\section{Analyze the airport operational characteristics}

This analysis is carried out to establish the airport typical operational scenario; the key elements of operational scenario include the airport runway operation mode, meteorological condition and traffic flow.

- Airport runway

There are two runways at the airport: runway $06 / 24$ for take-off and runway $07 / 25$ for landing, as seen in Fig. 4. So the segregated operation mode is chosen as runway operation mode of airport operational typical scenario.

- Meteorological data

The meteorological data from January to December.

2017 at NKG is obtained from the US National Oceanic and Atmospheric Administration (NOAA).

The pollution coefficient is the ratio of the wind frequency to the mean wind speed. The larger the pollution coefficient means the greater impact on the airport environment caused by the air pollutant emission. According to the statistics, the relevant parameters of the winds with different wind direction at NKG are given in Table 1.

As seen from Table 1, the pollution coefficient of the East (E) is 7.07 which is the greatest in all wind directions. The environmental impact with $\mathrm{E}$ wind direction is most serious; therefore, the $\mathrm{E}$ is chosen as meteorological condition of airport operational typical scenario.

- Air traffic flow data

The annual air traffic flow data of NKG in 2017, the distribution of air traffic flow and aircraft type in each hour is shown in Fig. 3. The air traffic flow data of airport operational typical scenario can be generated based on the distribution characteristic [51].

4. Ground transportation

Table 1 Wind parameters of different wind direction at NKG

\begin{tabular}{llll}
\hline Wind direction & Wind frequently & Mean wind speed $(\mathbf{m} / \mathbf{s})$ & Pollution factor \\
\hline E & 20.3 & 2.87 & 7.07 \\
ESE & 14 & 2.79 & 5.02 \\
SE & 7.8 & 1.87 & 4.17 \\
$N$ & 6.8 & 1.67 & 4.07 \\
NE & 6.8 & 2.22 & 3.06 \\
ENE & 5.5 & 2.32 & 2.37 \\
\hline
\end{tabular}




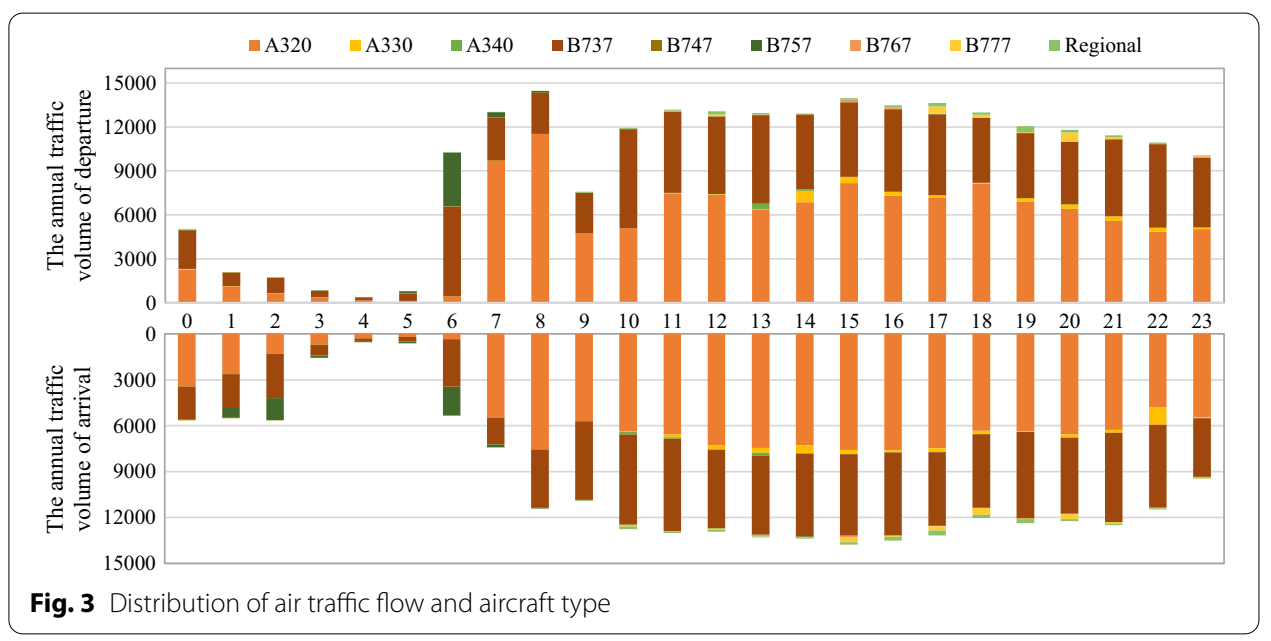

Fig. 3 Distribution of air traffic flow and aircraft type

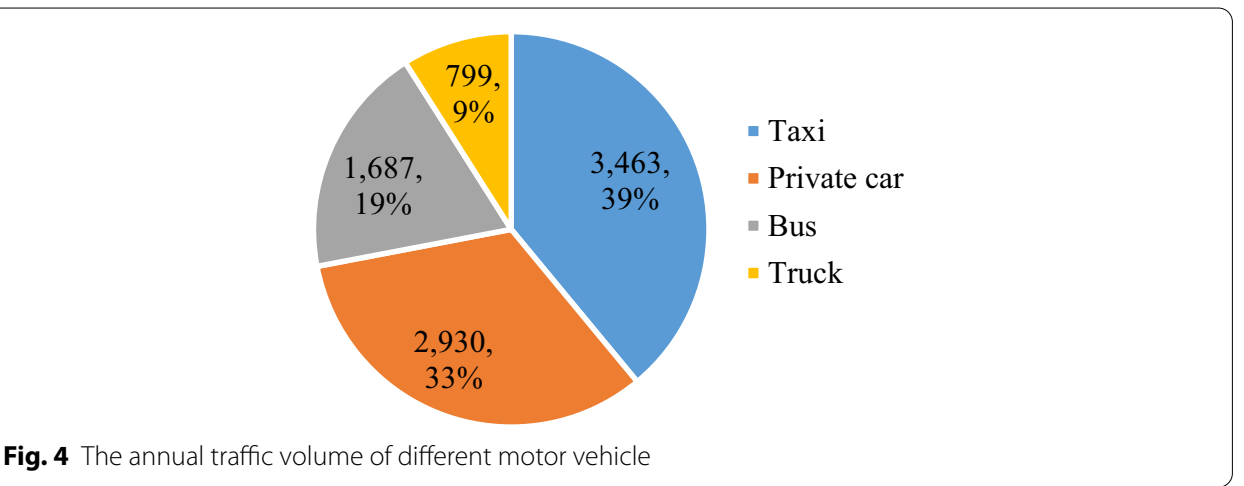

This paper considers the ground transportation related with airport operations, including taxi, private car, airport shuttle bus, truck, etc.; according to the statistics and calculation [52], in 2017, the average daily traffic volume of different motor vehicle is shown in Fig. 4.

\subsection{Find the air and noise emission receptor points}

1 Evaluation coordinate system

The coordinate system: the origin is midpoint of runway $07 / 25$, the $Y$ axis is along the direction of runway 07 , the $X$ axis is perpendicular to the $Y$ axis, and the $Z$ axis is the direction of the height, as seen in Fig. 5. 


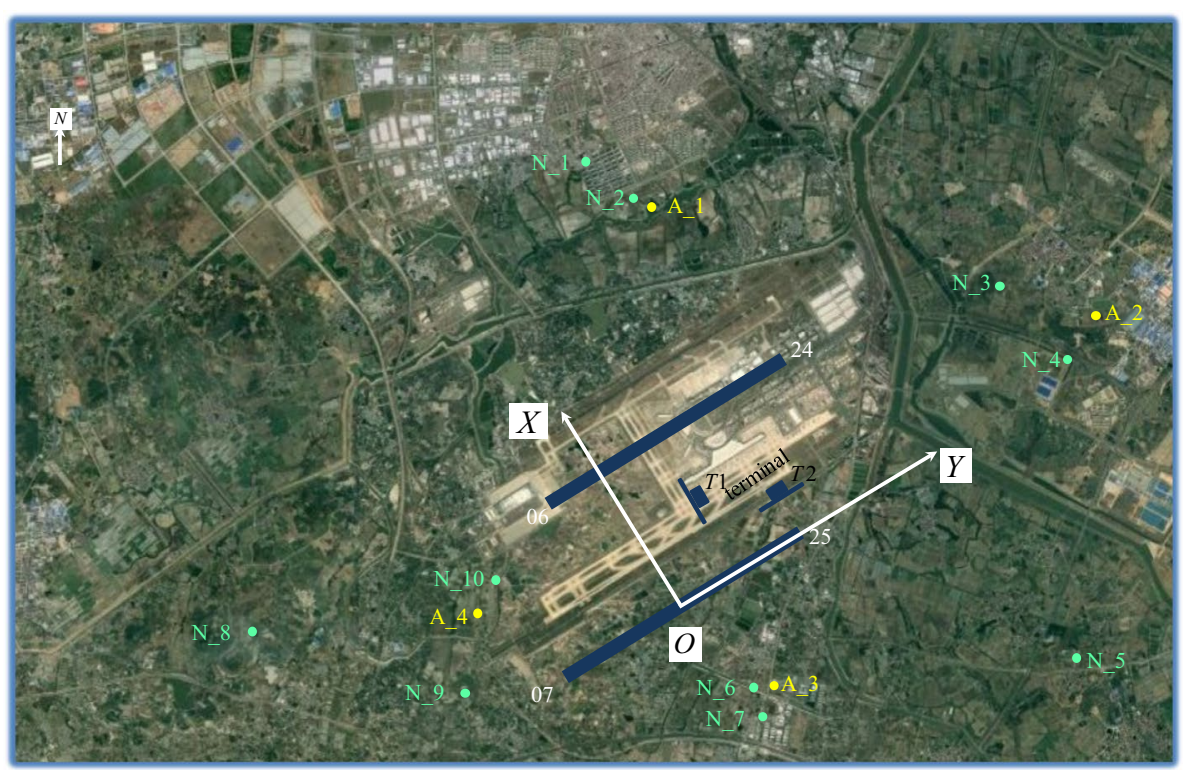

Fig. 5 Coordinate of concentration evaluation and evaluation range at NKG

Table 2 The information of air and noise emission receptor points

\begin{tabular}{llll}
\hline Point & Name & Coordinate $(\boldsymbol{x}, \boldsymbol{y})$ & Notes \\
\hline A_1 & Rongxing Community Groups & $(4247.6,1482)$ & Air emission receptor point \\
A_2 & Tuotang town & $(1859.4,6359.4)$ & Air emission receptor point \\
A_3 & Wanxi Village & $(-2088.1,785)$ & Air emission receptor point \\
A_4 & Pangjia Village & $(342.8,-3157.3)$ & Air emission receptor point \\
N_1 & Lukou Hospital & $(5602.6,1193)$ & Noise emission receptor point \\
N_2 & Lukou No. 2 Primary School & $(4528.8,1349.7)$ & Noise emission receptor point \\
N_3 & Tuotang Central Hospital & $(2373.5,5096)$ & Noise emission receptor point \\
N_4 & Nanjing Institute of Visual Arts & $(1463.2,5474.5)$ & Noise emission receptor point \\
N_5 & Xiaopeng Kindergarten & $(-2134.7,4399.6)$ & Noise emission receptor point \\
N_6 & Nanhang Jincheng College & $(-2033.1,682.2)$ & Noise emission receptor point \\
N_7 & Tongshan Middle School & $(-2535.4,342.9)$ & Noise emission receptor point \\
N_8 & Anming Community Health Service Centers & $(1497.7,-5150.5)$ & Noise emission receptor point \\
N_9 & Tugai Primary School & $(-367.6,-4108.6)$ & Noise emission receptor point \\
N_10 & Tugai Community Health Service Centers & $(724.5,-23,814)$ & Noise emission receptor point \\
\hline & & &
\end{tabular}

Table 3 Ambient air quality and noise standards

\begin{tabular}{llllll}
\hline & & NO $_{\boldsymbol{x}}$ & CO & HC & PM10 \\
\hline Air & Annual & $50 \mu \mathrm{g} / \mathrm{m}^{3}$ & $2 \mathrm{mg} / \mathrm{m}^{3}$ & $200 \mu \mathrm{g} / \mathrm{m}^{3}$ & $70 \mu \mathrm{g} / \mathrm{m}^{3}$ \\
& Daily & $100 \mu \mathrm{g} / \mathrm{m}^{3}$ & $4 \mathrm{mg} / \mathrm{m}^{3}$ & $2000 \mu \mathrm{g} / \mathrm{m}^{3}$ & $150 \mu \mathrm{g} / \mathrm{m}^{3}$ \\
& Hourly & $250 \mu \mathrm{g} / \mathrm{m}^{3}$ & $10 \mathrm{mg} / \mathrm{m}^{3}$ & & \\
Noise & Zone 1 & Zone 2 & & & \\
& $\leq 70 \mathrm{~dB}$ & $\leq 75 \mathrm{~dB}$ & & & \\
\hline
\end{tabular}




\subsubsection{Receptor points}

There are 14 positions chosen as the receptor points, 4 points for air emission and 10 points for noise emission. The air emission receptor points choose the densely populated areas at four directions: front, back, left and right. The noise emission receptor points choose the sensitive points (hospital, school and residential area) along the terminal route; the detail information of receptor points is given in Table 2.

\subsection{Emission standards}

To ensure that the environment is not broken, the Ministry of Environmental Protection has established ambient air quality standards (GB 3095-2012) [53] and noise standards (GB 9660-88) [49] in China; the standards related to this paper are shown in Table 3.

\subsection{AETC_A calculation}

The average daily air traffic volume of NKG is 574 . According to the distribution characteristics of air traffic flow and aircraft type, we generate daily air flight flow of NKG and use the flight flow data and meteorological data to calculate the air emission inventory;

Table 4 Emission inventory of each air pollution resource $(\mathbf{k g})$

\begin{tabular}{lllrr}
\hline Pollution resource & NO $_{\boldsymbol{x}}$ & CO & HC & PM10 \\
\hline Aircraft & 4191.78 & 2200 & 212.33 & 15.10 \\
GSE & 526.03 & 764.38 & 92.25 & 25.51 \\
Ground transportation & 443.84 & 1824.66 & 195.34 & 8.68 \\
\hline
\end{tabular}

Table 5 Daily pollutant concentration of each receptor point $\left(\mu \mathrm{g} / \mathrm{m}^{3}\right)$

\begin{tabular}{lllll}
\hline Receptor point & NO $_{\boldsymbol{x}}$ & CO & HC & PM10 \\
\hline A_1 & 26.43 & 21.03 & 1.41 & 0.25 \\
A_2 & 21.73 & 18.05 & 2.13 & 0.2 \\
A_3 & 35.99 & 27.69 & 3.22 & 0.41 \\
A_4 & 45.58 & 30.42 & 5.75 & 0.61 \\
\hline
\end{tabular}

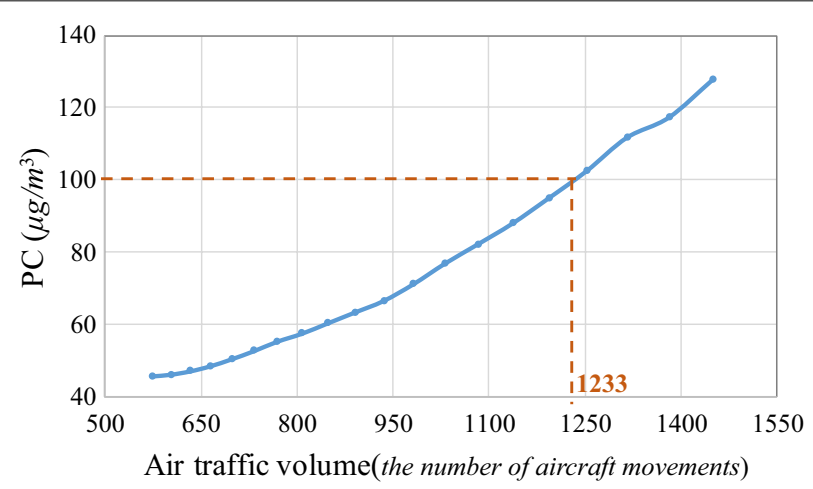

Fig. 6 The relationship of air traffic volume and PC 
Table 6 Noise level of each receptor point

\begin{tabular}{llll}
\hline Receptor point & Noise level $(\mathbf{d B})$ & Receptor point & $\begin{array}{l}\text { Noise } \\
\text { level } \\
\text { (dB) }\end{array}$ \\
\hline N_1 & & N_6 & 50 \\
N_2 & 33 & N_7 & 35 \\
N_3 & N_8 & 27 \\
N_4 & 32 & N_9 & 42 \\
N_5 & 43 & N_10 & 52 \\
\hline
\end{tabular}

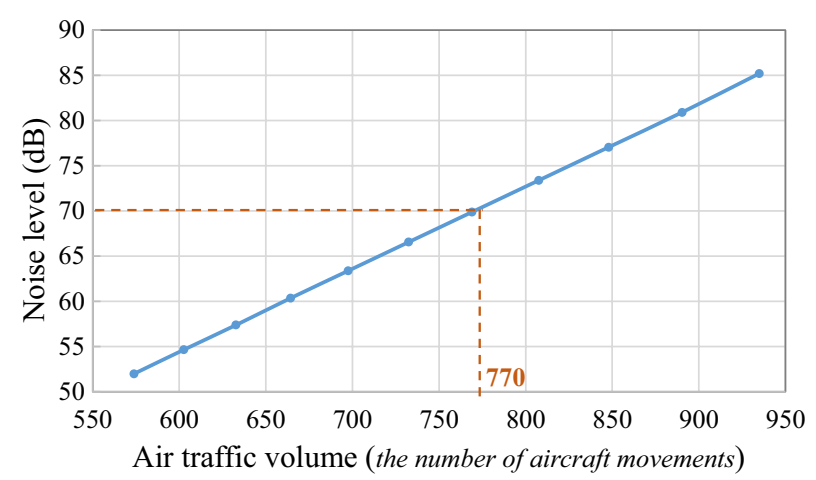

Fig. 7 The relationship of air traffic flow volume and NL

the results are shown in Table 4. The emission of aircraft, GSE and ground transportation is $63.03 \%, 14.43 \%$ and $23.54 \%$ of total emissions, respectively.

According to the pollutant concentration assessment model, the daily PC of each receptor points is calculated and shown in Table 5.

The $\mathrm{NO}_{x}$ pollutant concentration is obviously larger than other pollutant gases, but the daily air quality standards of $\mathrm{NO}_{x}$ are smaller than other pollutant gases, so the restricted gas of air emission is $\mathrm{NO}_{x}$. Besides, the $\mathrm{NO}_{x}$ pollutant concentration of A_4 is the maximum among four receptor points, so A_4 is the restricted receptor point. Therefore, $\mathrm{PC}$ is the $\mathrm{NO}_{x}$ pollutant concentration of $\mathrm{A} \_4$. The $\mathrm{PC}$ will increase with the daily air traffic volume. The relationship of air traffic flow and PC is shown in Fig. 6.

The PC and air traffic volume are approximately linear relationships. When the PC reaches daily air quality standard $-100 \mu \mathrm{g} / \mathrm{m}^{3}$, the corresponding air traffic volume is equal to 1233. This correspondence indicates that the pollutant concentration of the restricted point reaches the upper limit allowed by environmental protection; the air traffic volume is the maximum air traffic volume. In the other words, the AETC_A of NKG is 1233.

\subsection{AETC_N calculation}

Using the same air traffic flow and the noise level assessment model, the noise level of the receptor points is calculated, and the results are shown in Table 6. 
As seen from Table 6, the noise level of $\mathrm{N}_{-} 10$ is largest of all the receptor points, so $\mathrm{N} \_10$ is the noise emission restricted point, and the noise level of $\mathrm{N} \_10$ is NL.

The restricted point $N_{-} 10$ belongs to Zone 1 in the noise standard; the upper limit of noise standard is $70 \mathrm{~dB}$. The relationship of noise level and air traffic volume is shown in Fig. 6 . When the NL reaches $70 \mathrm{~dB}$, the corresponding air traffic volume is equal to 770 , which can be obtained from Fig. 7. This correspondence indicates that the noise level of the restricted point reaches the upper limit allowed by environmental protection; the air traffic volume is the maximum air traffic volume. In the other words, the AETC_N is 770 .

\section{Results and discussion}

This chapter mainly determines the daily AETC based on ambient air quality and noise standards, and discusses the results.

\subsection{Results}

The AETC_A and AETC_N are calculated in "AETC_A calculation" and "AETC_N calculation" section, respectively. The AETC needs to meet both air and noise emission limits.

According to Eq. (1), AETC=minimum (AETC_A, AETC_N)=minimum (1233, $770)=770$, the result shows that the daily AETC of NKG is limited by the noise emission.

In the calculation process of AETC_N, 10 points for noise emission were selected, mainly include sensitive points (hospital, school and residential area). As the selection of receptor points is not comprehensive enough, there are uncertainties in the results. In general, the confidence level is $95 \%$.

\section{Discussion}

This section mainly discusses the calculation results of AETC values in different time dimensions.

\section{- Annual AETC calculation}

The results above are calculated and determined for the daily AETC of NKG. The ambient air quality standard also requires annual and hourly standard, but the assessment model of noise level is mainly reflected in the daily standard, so the annual and hourly AETC are constrained by AETC_A.

Also taking NKG as an example, the annual $\mathrm{NO}_{x}$ pollutant concentration of receptor points can be calculated and the results are shown in Table 7.

The receptor point A_1 is still the restricted point because of the largest $\mathrm{NO}_{x}$ annual pollutant concentration, the annual PC of A_1 will increase with the annual air traffic volume, when the annual PC reaches $50 \mu \mathrm{g} / \mathrm{m}^{3}$, the annual air traffic volume also reaches 365,805 , that is to say AETC_A is 365,805 , and the AETC is equal to 365,805 .

Table 7 Annual pollutant concentration of each receptor point $\left(\mu \mathrm{g} / \mathrm{m}^{3}\right)$

\begin{tabular}{lllll}
\hline Receptor point & A_1 & A_2 & A_3 & A_4 \\
\hline$P C(x, y)\left(\mathrm{NO}_{x}\right)$ & 28.03 & 26.77 & 15.36 & 25.23 \\
\hline
\end{tabular}


Table 8 Hourly $\mathrm{NO}_{x} \mathrm{PC}$ of $\mathrm{A}_{-} \mathbf{1}\left(\boldsymbol{\mu g} / \mathrm{m}^{3}\right)$

\begin{tabular}{llllll}
\hline Hour & PC & Hour & PC & Hour & PC \\
\hline $0: 00-0: 59$ & 47 & $8: 00-8: 59$ & 68.61 & $16: 00-16: 59$ & 80.66 \\
1:00-1:59 & 27.1 & $9: 00-9: 59$ & 63.36 & $17: 00-17: 59$ & 81.01 \\
$2: 00-2: 59$ & 38 & $10: 00-10: 59$ & 71.84 & $18: 00-18: 59$ & 78.14 \\
$3: 00-3: 59$ & 4.96 & $11: 00-11: 59$ & 59.25 & $19: 00-19: 59$ & 82.32 \\
$4: 00-4: 59$ & 0.94 & $12: 00-12: 59$ & 56.42 & $20: 00-20: 59$ & 76.01 \\
$5: 00-5: 59$ & 9.53 & $13: 00-13: 59$ & 60.54 & $21: 00-21: 59$ & 70.42 \\
$6: 00-6: 59$ & 58.36 & $14: 00-14: 59$ & 57.12 & $22: 00-22: 59$ & 82.62 \\
$7: 00-7: 59$ & 64.12 & $15: 00-15: 59$ & 85.58 & $23: 00-23: 59$ & 66.21 \\
\hline
\end{tabular}

Table 9 AETC of different time dimension (the number of aircraft movement)

\begin{tabular}{llll}
\hline Time dimension & AETC_A & AETC_N & $\begin{array}{l}\text { AETC_min(AETC_A, } \\
\text { AETC_N) }\end{array}$ \\
\hline Hourly & 120 & - & 120 \\
Daily & 1233 & 770 & 770 \\
Annual & 365,805 & - & 365,805 \\
\hline
\end{tabular}

\section{- Hourly AETC calculation}

The hourly PC of A_1 can be calculated according to the distribution of air traffic flow, the results are given in Table 8.

The peak hour of air traffic volume in a day is 15:00-15:59, which has the largest PC $85.58 \mu \mathrm{g} / \mathrm{m}^{3}$. By increasing the air traffic volume, we can obtain the hourly AETC_A is 120 when the PC reaches to daily air quality standard $-250 \mu \mathrm{g} / \mathrm{m}^{3}$.

Thence, the hourly, daily and annual AETC can be obtain by different value methods, as seen in Table 9.

- Research limitations

The evaluation study of AETC in this article can help airport planners improve AETC and contribute to the sustainable development of the airport. The evaluation method in this article is mainly based on the air quality and noise standards, but not including the influence of surrounding buildings and structures on pollution diffusion and noise distribution are not considered.

\section{Conclusion}

With the sustain development of civil aviation as the background, airport ETC is necessarily used to restrict airport air traffic volume for environmental protection. This paper introduces a novel definition of AETC to represent airport ETC and hopes to make up for gaps in research on ETC of air traffic and initiate a new research direction about green civil aviation. The paper achieves following results:

1 A novel AETC definition is proposed to improve the evaluation of airport service capability and research on airport sustainability. 
2 The typical airport operational scenario is established by analyzing the characteristic of meteorological condition, air traffic flow, aircraft type distribution, etc.

3 The assessment method and process of AETC based on ambient air quality and noise standards are given in this paper according to the definition. It is a complete evaluation process including data processing, modeling and determination methods.

4. The numerical test of NKG shows us the quantitative results of the evaluation method and puts forward some suggestions for the development of NKG.

The evaluation method of this paper can help airport planners and city officials improve AETC by changing the airport operational mode including the air traffic flow distribution, aircraft type, etc. According to the limitations of this study, the future research work should modify the pollutant concentration and noise level models to evaluate more accurate results.

\section{Abbreviations}

ETC: Environmental traffic capacity; ATM: Air traffic management; LTO: Landing and take-off; ICAO: International Civil Aviation Organization; AEDT: Aviation Environmental Design Tool; AETC: Airport environment traffic capacity; NKG: Nanjing Lukou international airport; GSE: Ground support equipment.

\section{Acknowledgements}

The authors thank the person who provided meticulous and valuable suggestions for improving the paper.

\section{Authors' contributions}

Lili Wan is the main author of the current paper. Lili Wan contributed to the development of the ideas, design of the study, theory, result analysis and article writing. Qiuping Peng carried out the experimental work and the data collection and interpretation. Lei Gao finished the analysis and interpretation of data and drafted the manuscript. Yong Tian and Bojia Ye conceived and designed the experiments and undertook revision works of the paper. All authors read and approved the final manuscript.

\section{Funding}

This work is supported in part by the National Natural Science Foundation of China under Grants 61671237 and U1933119.

\section{Availability of data and materials}

Data sharing not applicable to this article as no data sets are generated or analyzed during the current study.

\section{Competing interests}

The authors declare that they have no competing interests.

\section{Author details}

${ }^{1}$ College of Economics and Management, Nanjing University of Aeronautics and Astronautics, Nanjing 210016, People's Republic of China. ${ }^{2}$ College of Civil Aviation, Nanjing University of Aeronautics and Astronautics, Nanjing 210016, People's Republic of China.

Received: 20 April 2020 Accepted: 21 October 2020

Published online: 02 November 2020

\section{References}

1. R. De Neufville, A. Odoni, Airport Systems Planning Design and Management, 2nd edn. (MC Graw Hill Education, New York, 2013)

2. C. Buchanan, Traffic in Towns (Her Majesty's Stationery Office, London, 1963)

3. B. Huang, Z. Pan, G. Wang, A methodology to control urban traffic noise under the constraint of environmental capacity: a case study of a double-decision optimization model. Transp. Res. D Transp. Environ. 41, 257-270 (2015). https://doi.org/10.1016/j.trd.2015.09.026

4. Y. Du, Y. Jia, J. Wu, M. Xu, S. Yang, Dynamic traffic control model based On traffic environmental capacity. J. Transp. Syst. Eng. Inf. Technol. 15(2), 36-41 (2015). https://doi.org/10.3969/j.issn.1009-6744.2015.02.006

5. X. Wang, H. Fu, J. Lu, Study on road section environmental traffic capacity model and algorithm under double constraints. Transp. Res. D Transp. Environ. 48, 14-19 (2016). https://doi.org/10.1016/j.trd.2016.07.005

6. E. Kadarsa, A. Lubis, A. Sjafruddin, Fairway traffic capacity in Indonesia. Procedia Eng. 171, 1443-1453 (2017). https:// doi.org/10.1016/j.proeng.2017.01.466 
7. P. Upham, C. Thomas, D. Gillingwater, Environmental capacity and airport operations: current issues and future prospects. J. Air Transp. Manag. 9(3), 145-151 (2003). https://doi.org/10.1016/S0969-6997(02)00078-9

8. S. Hasan, D. Long, G. Hart, Integrated analysis of airport capacity and environmental constraints, in Proceedings of 10th AIAA Aviation Technology, Integration, and Operations, VA, USA (2010)

9. M. Hu, Theory and Method of Air Traffic Flow Management (Science Press, Beijing, 2010)

10. C. Cetek, E. Cinar, F. Aybek, A. Cavcar, Capacity and delay analysis for airport maneuvering areas using simulation. Aircr. Eng. Aerosp. Technol. Int. J. 86(1), 43-55 (2013). https://doi.org/10.1108/AEAT-04-2012-0058

11. D. Welch, Y.N. Cho, N. Underhill, R. Delaura, Sector workload model for benefits analysis and convective weather capacity prediction, in Proceedings of 10th USA/Europe Air Traffic Management Research and Development Seminar, Chicago, USA (2013)

12. B. Rodríguez-Díaz, P.-T. Adenso-Díaz, A review of the impact of noise restrictions at airports. Transp. Res. D Transp. Environ. 50, 144-153 (2017). https://doi.org/10.1016/j.trd.2016.10.025

13. M. Masiol, R. Harrison, Aircraft engine exhaust emissions and other airport-related contributions to ambient air pollution: a review. Atmos. Environ. 95, 409-455 (2014). https://doi.org/10.1016/j.atmosenv.2014.05.070

14. B. Płanda, J. Skorupski, Methods of air traffic management in the airport area including the environmental factor. Int. J. Sustain. Transp. 11(4), 295-307 (2017). https://doi.org/10.1080/15568318.2016.1253801

15 S. Penn, S. Boone, B. Harvey, Modeling variability in air pollution-related health damages from individual airport emissions. Environ. Res. 156, 791-800 (2017). https://doi.org/10.1016/j.envres.2017.04.031

16 I.C. Dedoussi, S.R.H. Barrett, Air pollution and early deaths in the United States, part II: attribution of PM2.5 exposure to emissions species, time, location and sector. Atmos. Environ. 99, 610-617 (2014). https://doi.org/10.1016/j.atmos env.2014.10.033

17. S. Wan, Z. Gu, Q. Ni, Cognitive computing and wireless communications on the edge for healthcare service robots. Comput. Commun. (2019). https://doi.org/10.1016/j.comcom.2019.10.012

18. Q. Xia, H. Zuo, J. Yang, Evaluation of LTO cycle emissions from aircraft in China's Civil Aviation Airports. Acta Sci. Circumst. 28(7), 1469-1474 (2008). https://doi.org/10.13671/j.hjkxxb.2008.07.027

19. S.R.H. Barrett, R.E. Britter, Development of algorithms and approximations for rapid operational air quality modelling. Atmos. Environ. 42, 8105-8111 (2008). https://doi.org/10.1016/j.atmosenv.2008.06.020

20. S.R.H. Barrett, R.E. Britter, Algorithms and analytical solutions for rapidly approximating long-term dispersion from line and area sources. Atmos. Environ. 43, 3249-3258 (2009). https://doi.org/10.1016/j.atmosenv.2009.03.032

21. A. Ashok, I.H. Lee, S. Arunachalam, I.A. Waitz, S.H. Yim, S.R. Barrett, Development of a response surface model of aviation's air quality impacts in the United States. Atmos. Environ. 77, 445-452 (2013). https://doi.org/10.1016/j.atmos env.2013.05.023

22. ICAO, Doc9889: Airport Air Quality Manual (ICAO, Montreal, 2011)

23. J. Kurniawan, S. Khardi, Comparison of methodologies estimating emissions of aircraft pollutants, environmental impact assessment around airports. Environ. Impact Assess. Rev. 31(3), 240-252 (2011). https://doi.org/10.1016/j. eiar.2010.09.001

24. D. Wasiuk, M. Lowenberg, D. Shallcross, An aircraft performance model implementation for the estimation of global and regional commercial aviation fuel burn and emissions. Transp. Res. D Transp. Environ. 35, 142-159 (2015). https ://doi.org/10.1016/j.trd.2014.11.022

25. FAA, Aviation Environmental Design Tool (AEDT) Technical Manual Version 2c, U.S. DOT Volpe Center (2016)

26. V. Dragana, T. Nedeljko, An assessment of pollutant emissions due to air traffic at Nikola Tesla International Airport, Belgrade, and the link between local air quality and weather types. Transp. Res. D Transp. Environ. 56, 85-94 (2017). https://doi.org/10.1016/j.trd.2017.08.003

27. M. Alain, Environmental noise, sleep and health. Sleep Med. Rev. 11, 135-142 (2007)

28. W. Babisch, B. Beule, M. Schust, N. Kersten, H. Ising, Traffic noise and risk of myocardial infarction. Epidemiology 16, 33-40 (2005)

29. F. Minichilli, F. Gorini, E. Ascari, F. Bianchi, A. Coi, L. Fredianelli, G. Licitra, F. Manzoli, L. Mezzasalma, L. Cori, Annoyance judgment and measurements of environmental noise: a focus on Italian secondary schools. Int. J. Environ. Res. Public Health 15(2), 409-416 (2018). https://doi.org/10.3390/ijerph15020208

30. G. Licitra, E. Ascari, L. Fredianelli, Prioritizing process in action plans: a review of approaches. Curr. Pollut. Rep. 3(2), 151-161 (2017). https://doi.org/10.1007/s40726-017-0057-5

31. R.N. Lawton, D. Fujiwara, Living with aircraft noise: airport proximity, aviation noise and subjective wellbeing in England. Transp. Res. D Transp. Environ. 42, 104-118 (2016). https://doi.org/10.1016/j.trd.2015.11.002

32 K. Vogiatzis, Airport environmental noise mapping and land use management as an environmental protection action policy tool. The case of the Larnaka International Airport (Cyprus). Sci. Total Environ. 424, 162-173 (2012). https://doi.org/10.1016/j.scitotenv.2012.02.036

33. L. Gaetano, G. Paolo, F. Luca, S. Duccio, Noise mitigation action plan of Pisa civil and military airport and its effects on people exposure. Appl. Acoust. 84, 25-36 (2014). https://doi.org/10.1016/j.apacoust.2014.02.020

34. L. Gasco, C. Asensio, G. Arcas, Communicating airport noise emission data to the general public. Sci. Total Environ. 586, 836-848 (2017). https://doi.org/10.1016/j.scitotenv.2017.02.063

35. P. Gagliardi, L. Teti, G. Licitra, A statistical evaluation on flight operational characteristics affecting aircraft noise during take-off. Appl. Acoust. 134, 8-15 (2018). https://doi.org/10.1016/j.apacoust.2017.12.024

36. L. Li, T.T. Goh, D. Jin, How textual quality of online reviews affect classification performance: a case of deep learning sentiment analysis. Neural Comput. Appl. 32, 4387-4415 (2020). https://doi.org/10.1007/s00521-018-3865-7

37. Z. Gao, Y. Li, S. Wan, Exploring deep learning for view-based 3D model retrieval. ACM Trans. Multimed. Comput. Commun. Appl. (2020). https://doi.org/10.1145/3377876

38. S. Wan, X. Xu, T. Wang, Z. Gu, An intelligent video analysis method for abnormal event detection in intelligent transportation systems. IEEE Trans. Intell. Transp. Syst. (2020). https://doi.org/10.1109/TITS.2020.3017505

39. Z. Gao, H. Xuan, H. Zhang, S. Wan, K.K.R. Choo, Adaptive fusion and category-level dictionary learning model for multiview human action recognition. IEEE Internet Things J. 6(6), 9280-9293 (2019). https://doi.org/10.1109/ JIOT.2019.2911669 
40. S. Wan, R. Gu, T. Umer, K. Salah, X. Xu, Toward offloading internet of vehicles applications in 5 G networks. IEEE Trans. Intell. Transp. Syst. (2020). https://doi.org/10.1109/TITS.2020.3017596

41. ICAO, ICAO Supplement to Annex 16: Environment Protection (ICAO, Montreal, 2011)

42. Eurocontrol Experimental Center, Model Accuracy Summary Report for the Base of Aircraft Data (BADA) Revision 3.11 (EEC, Bretigny, 2012)

43. KB Environmental Sciences and Aerodyne Research, Quality Assurance Project Plan for the Development of a Commercial Aircraft Hazardous Air Pollutants Emissions Inventory Methodology (Environmental Protection Agency and the Federal Aviation Administration, Washington, DC, 2008)

44. ICAO, ICAO Annex 16: Aircraft Engine Emissions, 8th edn, vol. 2. (ICAO, Montreal, 2014)

45. R.L. Wayson, W. Bowlby, Inventorying airport air pollutant emissions. J. Transp. Eng. 114(1), 1-20 (1988)

46. Ministry of Environmental Protection, Technical Guide for the Preparation of Road Vehicle Air Pollutant Emission Inventory (GB 3095-2012) (Beijing, 2014)

47. D.B. Turner, Workbook of Atmosphere Dispersion Estimates, North Carolina (1970)

48. W. Li, X. Cheng, Emission coefficient of air pollution and its calculation method. Res. Environ. Sci. 6(4), 1-7 (1993). https://doi.org/10.13198/j.res.1993.04.36.liwz.003

49. National Standard of People's Republic of China, Measurement of Aircraft Noise Around Airport, GB9661-88 (1988), pp. 4-5

50. ICAO, Recommended Method for Computing Noise Contours Around Airports, Doc 9911 (2008)

51. S. Wan, Y. Xia, L. Qi, Y. Yang, M. Atiquzzaman, Automated colorization of a grayscale image with seed points propagation. IEEE Trans. Multimed. (2020). https://doi.org/10.1109/TMM.2020.2976573

52. L.F. Zhang, Z. Wang, S. Fang, Study on traffic capacity and demand of airport terminal curbside. J. Tongji Univ. (Nat. Sci.) 35(4), 486-490 (2007). https://doi.org/10.3321/j.issn:0253-374X.2007.04.011

53. Chinese Research Academy of Environmental Science. Ambient air quality standards. Ministry of Environmental Protection of the PRC, GB3095-2012 (2012)

\section{Publisher's Note}

Springer Nature remains neutral with regard to jurisdictional claims in published maps and institutional affiliations.

\section{Submit your manuscript to a SpringerOpen ${ }^{\circ}$ journal and benefit from:}

- Convenient online submission

- Rigorous peer review

- Open access: articles freely available online

- High visibility within the field

- Retaining the copyright to your article

Submit your next manuscript at $\gg$ springeropen.com 